\title{
KNOWLEDGE, ATTITUDE, AND REPORTED PRACTICES OF A GROUP OF MINISTRY OF HEALTH DENTISTS TOWARDS PATIENTS WITH DIABETES MELLITUS IN ALEXANDRIA, EGYPT
}

\begin{abstract}
Myriam A. Saad ${ }^{1} B D S$ Susan M. Saleh ${ }^{2} P h D$, Wafaa Essam Eldin ${ }^{2} P h D$
ABSTRACT

INTRODUCTION: Diabetes and its acute complications have become a significant health hazard worldwide. To date, there are no data on the awareness of dental professionals regarding the management of diabetic patients.

OBJECTIVES: The objective of this study was to assess the knowledge, attitude and reported practices of Ministry of Health dentists $(\mathrm{MOH})$ regarding the oral complications associated with Diabetes Mellitus.

MATERIALS AND METHODS: This study was a cross sectional descriptive survey of a sample of dentists working in the Egyptian Ministry of Health facilities, in Alexandria. The 349 participants were asked to complete a comprehensive, close-ended questionnaire, to assess the knowledge, attitude, and reported practices regarding diabetic patients. The first section was concerned with the demographic variables of the participating dentists. The second and third sections enquired about the participants' knowledge and attitudes regarding diabetic symptoms, while the forth section of the questionnaire assessed the respondents' reported practices concerning diabetic patients and actions taken toward the disease.

RESULTS: Dentists participated in the study (n= 349 from 400 with a response rate of $87.25 \%$ ) showed that Ministry of Health dentists had a good knowledge and favorable attitude toward diabetic patients visiting the Ministry of Health clinics, however, they had inadequate reported practices toward the same issue.

CONCLUSIONS: THE present study showed relatively high level of awareness of dental practitioners regarding diabetes. Therefore, designing appropriate training programs for oral health care providers in order to enhance their practices towards the diagnosis and management of oral complications of Diabetes is mandatory.

KEYWORDS: Diabetes Mellitus, knowledge, attitude, practice, dentists, Ministry of Health, Egypt.
\end{abstract}

1-Bachelor of Dental medicine and surgery 2007, Faculty of Dentistry, Alexandria University, Egypt.

2-Professor of Public health, Faculty of Dentistry, Alexandria University, Egypt.

Corresponding author:

E.mail: myriam.abdou.saad@gmail.com

\section{INTRODUCTION}

Although the dangers of diabetes have been recognized worldwide, available data on the awareness of dental professionals regarding the management of diabetic patients are rare. With the increasing longevity and effective diagnostic aids, the dentists will be treating more patients with Diabetes Mellitus in the near future. Therefore, it becomes essential for a dental surgeon to be aware of the medical and dental management of diabetic patients (1).

Diabetes mellitus is increasing in prevalence, especially in Asia and Africa. According to the World Health Organization (WHO), the greatest increase in the number of people with diabetes, by 2030, among the Middle Eastern countries, will be in Egypt, in close proximity to seven million diabetic cases (2).

Diabetes mellitus is a group of metabolic disorders characterized by hyperglycemia. It is associated with abnormalities in carbohydrate, fat, and protein metabolism, and results in chronic complications, including micro vascular, macro vascular, and neuropathic disorders (3). If diabetes is left uncontrolled for an extended period of time, it negatively affects the flow of salivary glands and results in xerostomia, sialosis, taste impairment and dental caries. Lichen planus, geographic tongue, abscesses, delayed wound healing, and frequent infections are also common oral manifestations of diabetes in addition to the failure of treatment procedures. Signs and symptoms of periodontal disease are considered major complications of diabetes mellitus, as well (4).

During recent years, concerns have been raised about the need to address the relationship between general health and oral health in the dental setting (5-8). In 2005, the CDC called for an increase of oral health awareness and oral health care of patients with diabetes at a state and national level (9).

In the year 2014, Hema (10) conducted a study among practicing dentists of Hubli-Dharwar city, India. A close ended questionnaire, with 18 items, was used to assess the attitude and practices of participating dentists. Ninety seven percent of the participants reported they knew how to assess oral complications of Diabetes. It was 
concluded that formal training of dentists regarding assessment and management of diabetic patients was significantly associated with attitudes and practices.

Since many dental patients may have undiagnosed diabetes, dentists should be well trained to detect and recognize such oral manifestations of the disease and refer the suspected undiagnosed patients to a physician for further diagnostic procedures. This might be a lifesaving condition. Given the increasing prevalence of diabetes, it is critical that dental professionals become better prepared to actively work with other health care providers in diabetes prevention and management (11). Considering the expected increase in prevalence of diabetes in Egypt (2), efficient health policies, appropriate preventive programs as well as effective multidisciplinary management of the oral implications of diabetes are needed. So, the overall goal of this study was to determine the knowledge, attitude and reported practices of the Ministry of Health dentists regarding diabetes mellitus patients, in Alexandria, Egypt.

\section{MATERIALS AND METHODS \\ Study design}

A descriptive cross sectional study design was adopted and was based on a structured questionnaire was completed by the participants.

Ethical consideration:

The approval of the Dental Research Ethics Committee at Faculty of Dentistry, Alexandria University was obtained followed by a letter from the faculty explaining the objective of the study and seeking approval of the Alexandria Directorate of Health Affairs in order to gain access to the Healthcare facilities. Furthermore, the permission of the participating dentists was obtained through a detailed explanation of the objectives of the research, in order to gain their trust and confidence as well as their full cooperation.

The current study adopted an analytical, cross-sectional design using a self-administered questionnaire. The questionnaire was pilot tested to ensure clarity of the questions and consistency.

All approached dentists in the visited $\mathrm{MOH}$ facilities were given detailed information regarding the study objectives prior to questionnaire distribution.

Participation of the dentists was on voluntary basis and all potential respondents were clearly advised that they had the right to comply or refuse participation. Participants were assured that the questionnaire is anonymous and confidentiality of the response and personal data were secured. Returning back the filled questionnaire was considered as an implied consent with no need for further written consent.

The present study was carried out to assess knowledge, attitudes and reported practices of dentists working in the Ministry of Health (MOH), in Alexandria, regarding the oral complications associated with Diabetes Mellitus, using a self administered, close-ended questionnaire.
A list of the total number of dentists working in the different health districts of Alexandria governorate was obtained from the directorate of health affairs. The list obtained from the directorate initially contained 1866 dentists who were working in 2015. It was estimated that a sample size of 400 would be representative of the whole dentists' population (12).

A random sample of dentists $(n=400)$ was selected from $\mathrm{MOH}$ settings using a proportional allocation technique. $\mathrm{MOH}$ facilities were randomly selected until covering the estimated sample size in each district.

Data were collected in five months period from March to July 2016 using a pre-tested questionnaire that was used for the same purpose in previous studies worldwide $(1,13)$. The initially approached sample consisted of 400 dentists, only 349 dentists agreed to complete the questionnaire, giving a response rate of $87.25 \%$.

The questionnaire consisted of 25-items arranged in four sections: demographic data, knowledge (10 questions), attitude (8 statements) and reported practices (7 questions) of the dentists regarding patient with Diabetes Mellitus. The first section was concerned with the demographic information of the participants such as age, gender, academic position, average year of practice, having diabetes or having relatives who have diabetes and prior participation in any courses related to diabetes, the second section was concerned with the participants' knowledge of Diabetes Mellitus disease, specifically, oral conditions related to this disease and was included in ten questions. The first question was about the most affected gender with Diabetes Mellitus, the second was about the best measure and the golden standard for assessing glycemic control, and the third question enquired about the normal value of Glycated haemoglobin (A1C). The fourth, fifth, seventh, eight and tenth questions were about the most common cytokines associated with periodontal inflammation among patients with diabetes and their oral conditions related to the disease.

Question six investigated the main barriers to measure blood glucose level for patients in the $\mathrm{MOH}$ clinics. Finally, the ninth question was about genetic influence.

The third section was related to dentists' attitudes toward the diabetic patients.

The first six questions were about attitude and beliefs imbedded in the mind of dentists toward Diabetes Mellitus from their education and knowledge. The seventh question was asking the dentists if they feel that they have a role to diagnose Diabetes Mellitus in dental practice.

The final question in this section was about the role of public health in educating the patients about their condition and filtering the dentists who believe that education make a difference in patients' condition compared to those who do not give any interest to this major concern. 
The last section was reported practices This section included seven questions about the reported practices of the dentists while managing the patient with Diabetes Mellitus. They were asked if they received enough training on how to deal with patients and if they have glucose monitor in their clinic to make analysis for diabetic patients and record their condition in a file. Finally, participants were asked about referring suspected patients to physician to diagnose the disease and coordinate with him in case the condition was positive.

\section{Statistical analysis:}

Collected data were fed to the computer and analyzed by IBM-SPSS (Version 22.0) software package for Microsoft Windows. The developed graphs were constructed using Microsoft excel software.

Descriptive statistics were calculated as frequencies and percentages. Three scales to assess knowledge, attitude and reported practice regarding Diabetes Mellitus were developed as follows:

- For the 10 questions of "knowledge about Diabetes Mellitus", each correct answer was given a score of 1 while an incorrect answer was assigned a score of 0 . Individual scores were summed up to yield a total score ranged from $0-10$. This total score was then divided by the maximum score 10 to get the percent for each participant. Knowledge percentages were categorized into; low (less than 50\%), moderate (50\%$75 \%$ ) and high (more than $75 \%$ ).

- Each item of the 8 statements of dentists' attitudes toward Diabetes Mellitus was given a score according to dentists' responses as follows; agree $=3$, neutral=2, and disagree $=1$. These scores were then summed up for each participant and considered either a positive attitude (if the total attitude score ranged from 19-24), neutral attitude (total attitude score $=14-18$ ), and negative attitude (if the total attitude score was less than 14).

- Dentists' reported practices related to Diabetes Mellitus were evaluated from seven questions. Each correct answer for these seven questions was given a score of one point and then was summed with the other correct items to create an index ranging potentially from 0 to 7 and organized in four scores; no practice at all (the participants did not answer any correct answer in the practice questions), poor practice (score ranged from 12 ), fair practice (score ranged from 3-4), good practice (score ranged from 5-7).

The Pearson correlation coefficient (r) is used to measure the strength and direction of the relationship between each 2 scales of knowledge, attitude and reported. Significance of correlations was detected at the $5 \%$ level (14).

\section{RESULTS}

Table A, B, C shows the questions of the 25 items questionnaire with the most favorable answers. Demographic data and personal characteristics of the responding dentists are presented in table (1).
Table A: Dentists' knowledge about Diabetes Mellitus and oral health related conditions

\begin{tabular}{|c|c|c|c|}
\hline \multicolumn{2}{|c|}{ Knowledge items } & No & $\%$ \\
\hline \multirow{3}{*}{ More affected gender } & Male & 91 & 26.1 \\
\hline & Female * & 247 & 71.0 \\
\hline & I don't know & 10 & 2.9 \\
\hline \multirow{5}{*}{ Best measure } & HbA1c * & 233 & 66.8 \\
\hline & fasting blood glucose & 95 & 27.2 \\
\hline & oral glucose tolerance test & 10 & 2.9 \\
\hline & None of the above & 9 & 2.6 \\
\hline & don't know & 2 & 0.6 \\
\hline \multirow{5}{*}{$\begin{array}{l}\text { HbA1c Glycemic } \\
\text { index normal value }\end{array}$} & $<6 \% *$ & 199 & 57.3 \\
\hline & $7-10 \%$ & 98 & 28.2 \\
\hline & $>10 \%$ & 20 & 5.8 \\
\hline & None of the above & 26 & 7.5 \\
\hline & do not know & 4 & 1.2 \\
\hline \multirow{5}{*}{$\begin{array}{l}\text { The most common } \\
\text { cytokine associated } \\
\text { with periodontal } \\
\text { inflammation among } \\
\text { patients with diabetes }\end{array}$} & Prostaglandins & 44 & 12.6 \\
\hline & Interleukin(1L)-1B & 62 & 17.8 \\
\hline & TNF & 23 & 6.6 \\
\hline & All of the above * & 218 & 62.6 \\
\hline & do not know & 1 & 0.3 \\
\hline \multirow{6}{*}{$\begin{array}{l}\text { Oral condition you } \\
\text { would associate with } \\
\text { the oral } \\
\text { manifestations of } \\
\text { Diabetes Mellitus }\end{array}$} & Xerostomia & 19 & 5.4 \\
\hline & Periodontal diseae & 28 & 8.0 \\
\hline & Dental caries & 11 & 3.2 \\
\hline & Taste impairment & 19 & 5.4 \\
\hline & All of the above * & 272 & 77.9 \\
\hline & do not know & 0 & 0.0 \\
\hline \multirow{2}{*}{$\begin{array}{l}\text { Diabetes mellitus } \\
\text { causes oral fungal } \\
\text { infection }\end{array}$} & True * & 315 & 90.3 \\
\hline & False & 34 & 9.7 \\
\hline \multirow[b]{2}{*}{$\begin{array}{l}\text { One of systemic } \\
\text { complications of } \\
\text { Diabetes Mellitus is } \\
\text { alteration in wound } \\
\text { healing }\end{array}$} & True * & 335 & 96.0 \\
\hline & False & 14 & 4.0 \\
\hline \multirow{2}{*}{$\begin{array}{l}\text { There is a strong } \\
\text { genetic influence in } \\
\text { acquiring type } 2 \\
\text { Diabetes Mellitus }\end{array}$} & True * & 261 & 74.8 \\
\hline & False & 88 & 25.2 \\
\hline \multirow{2}{*}{$\begin{array}{l}\text { One of the macro } \\
\text { vascular } \\
\text { complications of } \\
\text { Diabetes Mellitus is } \\
\text { retinopathy }\end{array}$} & True * & 197 & 56.4 \\
\hline & False & 152 & 43.6 \\
\hline
\end{tabular}

* Correct answer 
Table B: Dentists' attitude regarding Diabetes Mellitus

\begin{tabular}{|l|c|c|c|c|c|c|}
\hline \multirow{2}{*}{ Attitude items } & \multicolumn{2}{|c|}{$*$ Agree } & \multicolumn{2}{c|}{ Disagree } & \multicolumn{2}{c|}{ Neutral } \\
\cline { 2 - 7 } & No & $\%$ & No & $\%$ & No & $\%$ \\
\hline $\begin{array}{l}\text { Individuals with } \\
\text { uncontrolled diabetes } \\
\text { are at an increased risk } \\
\text { for oral candidosis }\end{array}$ & 315 & 90.3 & 7 & 2.0 & 27 & 7.7 \\
\hline $\begin{array}{l}\text { Diabetes increases the } \\
\text { risk of Xerostomia (dry } \\
\text { mouth) leading to higher } \\
\text { risk for caries }\end{array}$ & 308 & 88.3 & 7 & 2.0 & 34 & 9.7 \\
\hline $\begin{array}{l}\text { Research shows that } \\
\text { treatment of periodontal } \\
\text { disease may improve } \\
\text { Glycemic control }\end{array}$ & 199 & 57.0 & 63 & 18.1 & 87 & 24.9 \\
\hline $\begin{array}{l}\text { Periodontal disease may } \\
\text { worsen Glycemic } \\
\text { control }\end{array}$ & 201 & 57.6 & 60 & 17.2 & 88 & 25.2 \\
\hline $\begin{array}{l}\text { Poor diabetes control } \\
\text { encourages the growth } \\
\text { of oral bacteria }\end{array}$ & 308 & 88.3 & 6 & 1.7 & 35 & 10.0 \\
\hline $\begin{array}{l}\text { Diabetes mellitus causes } \\
\text { nephropathy as a } \\
\text { complication }\end{array}$ & 284 & 81.8 & 13 & 3.7 & 50 & 14.4 \\
\hline $\begin{array}{l}\text { I feel that I have a role } \\
\text { as a dentist in the } \\
\text { diagnosis of Diabetes } \\
\text { Mellitus }\end{array}$ & 297 & 85.1 & 4 & 1.1 & 48 & 13.8 \\
\hline $\begin{array}{l}\text { Educating patients with } \\
\text { diabetes about the oral } \\
\text { complications of } \\
\text { Diabetes Mellitus should } \\
\text { be a major concern for } \\
\text { the dentist }\end{array}$ & 289 & 82.8 & 7 & 2.0 & 53 & 15.2 \\
\hline
\end{tabular}

*Favorable answer.

Table C: Dentists' reported practices regarding Diabetes Mellitus

\begin{tabular}{|l|c|c|c|c|}
\hline \multirow{2}{*}{ Reported practice items } & \multicolumn{2}{c|}{ Yes } & \multicolumn{2}{c|}{ No } \\
\cline { 2 - 5 } & No & $\%$ & No & $\%$ \\
\hline $\begin{array}{l}\text { Received enough training on how to } \\
\text { deal with diabetic patients in dental } \\
\text { practice }\end{array}$ & 185 & 53.0 & 164 & 47.0 \\
\hline Have a glucose monitor in the office & 46 & 13.2 & 303 & 86.8 \\
\hline $\begin{array}{l}\text { Perform in office blood glucose } \\
\text { measurement for patients with diabetes } \\
\text { condition }\end{array}$ & 50 & 14.3 & 299 & 85.7 \\
\hline $\begin{array}{l}\text { Refer a patient to make a Diabetes } \\
\text { Mellitus analysis and it was positive }\end{array}$ & 226 & 64.8 & 123 & 35.2 \\
\hline $\begin{array}{l}\text { Document the diabetic condition in the } \\
\text { patient's file }\end{array}$ & 218 & 62.5 & 131 & 37.5 \\
\hline $\begin{array}{l}\text { Advice patients with diabetes about } \\
\text { periodontal risks }\end{array}$ & 256 & 73.4 & 93 & 26.6 \\
\hline $\begin{array}{l}\text { Consult with a physician for evaluation } \\
\text { of the diabetic case prior to treatment }\end{array}$ & 202 & 57.9 & 147 & 42.1 \\
\hline
\end{tabular}

Table 1: Description of the study sample $(\mathrm{N}=349)$ in relation to demographic and personal variables

\begin{tabular}{|c|c|c|c|}
\hline \multicolumn{2}{|c|}{ Variables } & No & $\%$ \\
\hline \multirow{4}{*}{ Age (years) } & $<30$ & 140 & 40.1 \\
\hline & 30- & 126 & 36.1 \\
\hline & $40-$ & 48 & 13.8 \\
\hline & $50-60$ & 35 & 10.0 \\
\hline \multirow{2}{*}{ Gender } & Male & 130 & 37.2 \\
\hline & Female & 219 & 62.8 \\
\hline \multirow{2}{*}{ Specialty } & General practitioner & 249 & 71.3 \\
\hline & Specialist & 100 & 28.7 \\
\hline \multirow{8}{*}{$\begin{array}{l}\text { Type of } \\
\text { specialty }\end{array}$} & Oral surgery & 37 & 36.6 \\
\hline & Periodontics & 20 & 19.8 \\
\hline & Dental public health & 13 & 12.9 \\
\hline & Conservative & 11 & 10.9 \\
\hline & Pedodontic & 9 & 8.9 \\
\hline & $\begin{array}{c}\text { Removable } \\
\text { prosthodontics }\end{array}$ & 5 & 5.0 \\
\hline & Orthodontics & 3 & 3.0 \\
\hline & Egyptian fellowship & 3 & 3.0 \\
\hline \multirow{4}{*}{$\begin{array}{l}\text { Years of } \\
\text { experience }\end{array}$} & $<5$ & 122 & 35.0 \\
\hline & 5- & 91 & 26.1 \\
\hline & $10-$ & 91 & 26.1 \\
\hline & $20+$ & 45 & 12.9 \\
\hline \multirow{2}{*}{ Working time } & Full time & 268 & 76.8 \\
\hline & Part time & 81 & 23.2 \\
\hline \multirow{2}{*}{$\begin{array}{l}\text { Diabetes } \\
\text { history }\end{array}$} & Yes & 186 & 53.3 \\
\hline & No & 163 & 46.7 \\
\hline \multirow{2}{*}{$\begin{array}{l}\text { Training } \\
\text { courses }\end{array}$} & Yes & 209 & 59.9 \\
\hline & No & 140 & 40.1 \\
\hline \multirow{4}{*}{$\begin{array}{l}\text { Hours of } \\
\text { training }\end{array}$} & $<1 \mathrm{~h}$ & 41 & 19.6 \\
\hline & $1-4 \mathrm{~h}$ & 93 & 44.5 \\
\hline & 5-10h & 56 & 26.8 \\
\hline & $>10 \mathrm{~h}$ & 19 & 9.1 \\
\hline
\end{tabular}

More than half of the sample consisted of females accounting for $62.8 \%$, who were less than 30 years of age (40.1\%). With regard to qualification, most of participants were general practitioners having a bachelor's degree (71.3\%), nearly one third were oral surgeons (36.6\%), followed by periodontists (19.8\%) and dental public health dentists only represented $12.9 \%$. According to years of experience, 35\% have spent less than five years in Alexandria $\mathrm{MOH}$, compared to $12.9 \%$ who had twenty years of experiences, with $76.8 \%$ working full time.

$53.3 \%$ of the sample reported that either themselves or a close family member had diabetes, and 59.9\% have already attended continuing educations courses mostly of 1-4 hours (44.5\%), whereas only $9.1 \%$ received training for more than 10 hours since graduation

(table 1). Data in figure (1) show the overall scores of knowledge of the participating dentists regarding diabetes mellitus and related oral conditions. Nearly one half of the dentists (55\%) scored high, 35\% showed a medium level of knowledge and only $10 \%$ had a low level of 
knowledge with regard to diabetes mellitus. Figure 2 shows the dentists' perceived barriers to perform blood glucose analysis in dental clinics. The most dominant cause was lack of resources (41.8\%), followed by lack of knowledge and lack of time (18.1\% both). Patient's resistance was found to be the least barrier accounting for only $4.6 \%$.

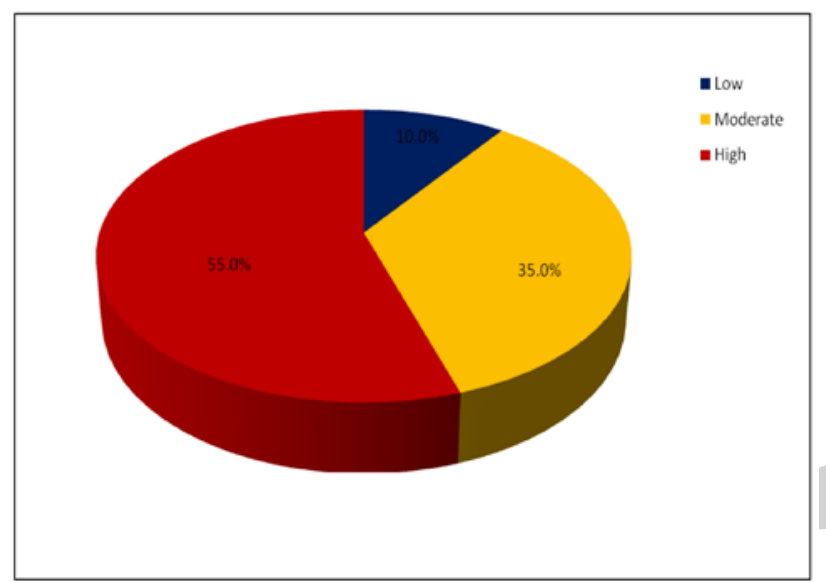

Figure (1): Overall knowledge scores of the study sample regarding diabetes mellitus.

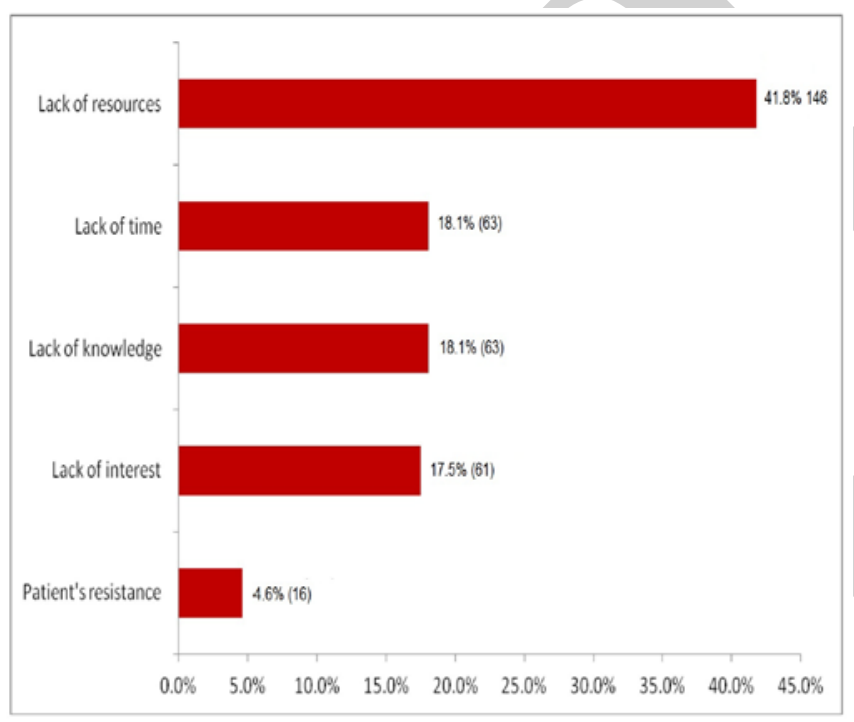

Figure (2): Dentists' perceived barriers to perform blood sugar level in the dental clinic.

The scores of dentists' attitudes towards diabetes mellitus are shown in figure 3 . The majority (83\%) of the respondents had a positive attitude towards diabetes mellitus. Those who scored neutral on the attitude scale represented $17 \%$, while no one had a negative attitude regarding diabetes mellitu

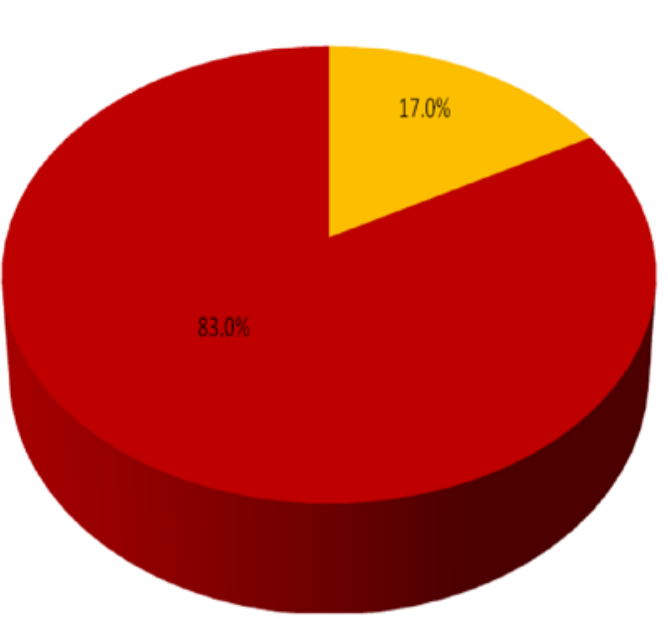

Neutral

-Positive

Figure (3): Attitude scores of the study sample regarding diabetes mellitus.

Scores of dentists' reported practice regarding diabetes mellitus are shown in figure 4. Results showed that less than half (39\%) of the dentists scored fair for the reported practice of diabetes mellitus, while about one third of the respondents had a good score (32.1\%). Meanwhile, only $14.6 \%$ and $14.3 \%$ had a poor practice and no practice at all regarding management of diabetic cases, respectively. Table (2) shows the correlation between knowledge, attitudes and reported practices of dentists working in the different $\mathrm{MOH}$ facilities, Alexandria Egypt

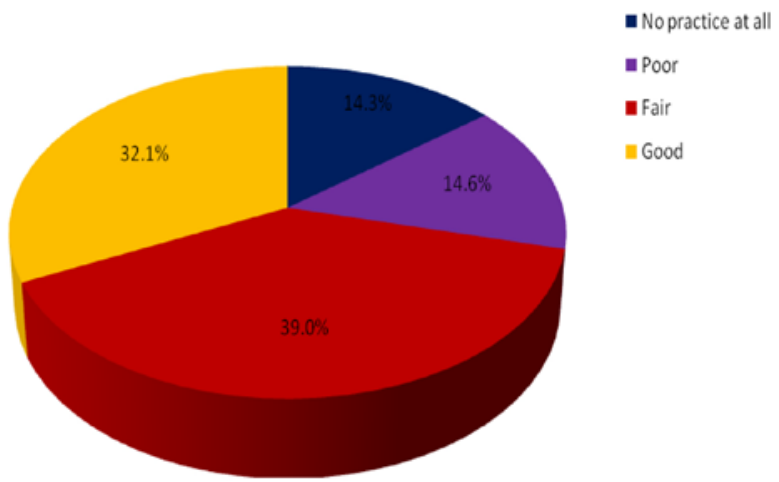

Figure (4): Dentists' reported practices regarding diabetes mellitus 
Table 2: Correlation coefficient between knowledge, attitudes and reported practices of dentists working in MOH facilities, Alexandria.

\begin{tabular}{|l|c|c|}
\hline \multicolumn{1}{|c|}{ Correlation } & $\mathrm{r}^{* *}$ & $\mathrm{P}$ \\
\hline $\begin{array}{l}\text { Knowledge total score-Attitude total } \\
\text { score }\end{array}$ & 0.369 & $0.001^{*}$ \\
\hline $\begin{array}{l}\text { Knowledge total score-Practice total } \\
\text { score }\end{array}$ & 0.272 & $0.001^{*}$ \\
\hline Attitude total score-Practice total score & 0.163 & $0.002^{*}$ \\
\hline
\end{tabular}

Pearson correlation coefficient:

$* \mathrm{P}<0.05$

** r: Correlation coefficient; Weak (0.01-0.24),

Intermediate (0.25-0.74), Strong (0.75-0.99)

There is a positive intermediate correlation detected between the three items. The relation was found to be significant $\mathrm{p}<0.05$ showing intermediate correlation. The only weak correlation was between attitude and practice scores.

For the relation between independent variables and knowledge attitudes and reported practices scores. Nearly the same percentage of males (56.9\%) and females (53.9\%) scored high on the overall knowledge scale while a significantly higher percentage of males (14.6\%) than females $(7.3 \%)$ scored low in the overall knowledge scale $(\mathrm{P}=0.03)$.

Regarding qualification degree, specialist dentists showed significantly higher level of knowledge (78\%), (P $=0.001)$, periodontists, pedodontists and orthodontics were the most knowledgeable groups about Diabetes Mellitus. On the other hand, dental public health and Egyptian fellowship dentists had a moderate level of knowledge accounting for $30.8 \%$ and $33.3 \%$ respectively, also showing a statistically significant difference $(\mathrm{P}=$ 0.011).

A higher percentage (11.9\%) of dentists having low knowledge regarding Diabetes Mellitus was detected among adults working full time in the $\mathrm{MOH}$ facilities, although they had the highest overall knowledge scores (56.3\%), showing statistically significant difference $(\mathrm{p}=0.018)$.

Participants who had diabetes or had diabetes history in family as well as those who attended continuing education courses were the most knowledgeable accounting for $60.8 \%$, and $67.9 \%$, respectively, showing a statistically significant difference $(\mathrm{P}=0.032$ and $\mathrm{P}=$ 0.01 respectively). The highest knowledge was detected among those who attended courses more than ten hours (89.5\%), whereas the lowest level of knowledge was among those who attended educational courses less than one hour $(58.5 \%)$, showing a statistically significant difference ( $P=0.003)$, as well. For the relations between attitude scores of participants toward Diabetes Mellitus dentists attended continuing education courses was the only independent variable showing a statistically significant difference in relation to Diabetes Mellitus where $90 \%$ of the participants had a significant positive attitude $(\mathrm{p}<0.001)$.

For the relation between reported practice scores regarding Diabetes Mellitus and the different studied variables. Female (35.2\%) and Specialists had the highest percentage (48\%) of good practice scores showing a significant difference ( $\mathrm{p}=0.001$, for each). On the other hand, $46.7 \%$ of the dentists working more than 20 years had the highest percentage of good practice scores. $(\mathrm{P}=0.033)$.

Dentists with a diabetes history in the family (36\%), and those who received continuing education courses (42\%) for more than 10 hours $(63.2 \%)$ had good reported practice scores $(\mathrm{P}=0.050, \mathrm{P}=0.001$ and $\mathrm{P}=0.081$, respectively).

\section{DISCUSSION}

Diabetes and its oral implications have become a significant health hazard worldwide, particularly in the Egyptian subcontinent (2). To date, there are no available data on the awareness of dental professionals regarding the management of diabetic patients. With the increasing disease prevalence and effective diagnostic tools, dentists are expected to treat more patients with Diabetes Mellitus in the near future, thus requiring higher awareness of the interdisciplinary management of the disease (1).

The response rate among the study sample was $87.25 \%$, which is considered one of the highest among all the reviewed studies that have been carried out on the same topic previously $(1,15)$. Most facilities were visited many times to overcome the non availability of some dentists in work places as well as the lack of interest of others to answer the questionnaire.

Females represented more than half of the sample (table 1). This is probably because males prefer to travel and work abroad. Moreover, Ministry of Health authorities employ female dentists in urban governorates, such as Alexandria, mostly for logistical reasons. The male to female ratio in the current study is, yet, consistent with the fact that more than half of the newly dental graduates are females as confirmed in the students' affairs records. Furthermore, questionnaires were mostly answered and returned back after dentists finished their patients' examination at the clinics, and males usually quickly left after finishing their duty, so they were not always available (table 1 ).

Dentists with post graduate degree represented only one quarter of the study sample.

About half of the sample had either diabetes or history of diabetes in their family which is a relatively high percentage that indicates increasing prevalence of the disease (table1). This percentage is slightly higher than that reported by Boyed in the year 2008 (13) where nearly $40 \%$ of dental hygienists suffered from diabetes themselves or their immediate family. 
The results of the present study also revealed that more than half of sample selected from Ministry of Health dentists, in Alexandria, have attended training courses about diabetes mellitus (table1). The present findings are not in agreement with other studies like Saxena and Esmeili $(1,15)$ reporting that the majority of dentists never attended any courses about the subject.

Knowledge of selected sample of Ministry of Health dentists in Alexandria was impressive since more than half of the study sample had high knowledge (figure 1),which is consistent with the results reported by Saxena et al in the year 2016 (1), in India. In the year 2008 Boyed (13), on the other hand, demonstrated a need for enhancing knowledge of dental hygienists about diabetes as it applies to clinical patient care.

This high knowledge of participants could be attributed to one fact that diabetes mellitus is included in the undergraduate curriculum of different departments topics. Furthermore, $\mathrm{MOH}$ is trying to increase knowledge about diabetes mellitus throw training courses due to its high prevalence among patients attending $\mathrm{MOH}$ facilities.

The $\mathrm{MOH}$ dentists reported that the most common barrier for appropriate diagnosis of diabetes mellitus was the lack of resources (figure 2), which hinders good quality practice even with the adequate knowledge and attitude. The second barrier was lack of knowledge regarding the use of glucometer, as a routine practice. Patients' resistance, on the other hand, was found to be the least encountered barrier (figure 2) which is probably attributed to the low education of the patients generally attending the $\mathrm{MOH}$ clinics, coupled with the dentists' negligence of patients' autonomy. The present findings are not consistent with Esmeili (15) who recorded in the year 2010 patients' resistance as a third barrier.

The most encouraging part of the present research was that the majority of the respondents had a positive attitude regarding patients with Diabetes Mellitus while few dentists showed neutral attitude toward the subject and no negative attitude was reported (figure 3). This result is not in agreement with Saxena in the year of 2016 (1) who reported negative attitude toward the same issue.

Despite the adequate attitude and knowledge, yet, only one third of the respondents had a good practice score whereas the majority of the sample scored fair. A high percentage showed no practice at all (figure 4), and few dentists reported poor practices. This is partly similar to the results of Esmeili in the year 2010 (15) who found that most dentists in his overall study sample did not feel confident in dealing with patients with diabetes in the dental setting. Formal training, however, made a significant difference in feelings of confidence and dentists' reported behavior.

The present findings showed low level of practice among the study sample regarding diabetes. The knowledge aspect of the questionnaire clearly depicted that the participant dentists had theoretical knowledge about certain aspects of diabetes but lagged behind when it came to the management of medical emergencies in the dental office. Therefore, there is an urgent need to implement the use of Blood Glucose Level (BGL) monitoring devices on a routine basis, as well as prescribing prophylactic antibiotics to diabetics and counseling patients for using oral hygiene aids. In order to increase the oral health care awareness for diabetes, inter-professional learning experiences to enhance a multidisciplinary approach for diabetes care should be created together with increasing the available resources of the $\mathrm{MOH}$ facilities. More workshops on diabetes should be organized for the dental practitioners to keep them abreast of the latest trends in management of patients with Diabetes Mellitus. This would definitely help them to provide better services for a diabetic patient and minimize the incidence of the dental emergencies associated with dental treatment.

On the other hand, in the year 2014 Hema (10) found that attitude and practice toward patients with diabetes were better among dentists with higher qualification, showing a positive correlation between attitude and practice which is not consistent with the present results as the attitude toward the disease was perfect while the practice was very poor, in addition to the weak correlation between attitudes and reported practices $(\mathrm{r}=$ 0.163) (table 2).

Participants who had diabetes or had diabetes history in family were the highest knowledgeable dentists in addition to those who attended continuing education courses more than ten hours, whereas the lowest level of knowledge was found among those who attended educational courses less than one hour. The present findings are logic since being a diabetic patient probably motivated the participants to increase their knowledge about the oral complications and management of the disease .Furthermore, this proves that continuous education for dentists seems to be even more important than working time, since a high percentage of those who had low overall knowledge about diabetes were full time dentists However, Boyd (13) reported four or fewer hours of diabetes education in the entry level of dental hygiene programs, with only $50.4 \%$ having completed more than 4 hours of continuing professional education since graduation .

The current results also agree with the study carried out among Indian dentists where Hema (10) found that attitude toward patients with diabetes was better among the dentists with higher educational qualification and those who had received formal training. Thus, designing strong curriculum objectives for oral health care providers in order to enhance their awareness towards diabetes is the need of the hour. Dentists, who had history of diabetes, had the highest percentage of good practice, which is logic because they are probably more interested in their medical condition and thus are more able to provide adequate and appropriate service for their diabetic patients.

Finally results revealed that dentists who attended courses on Diabetes Mellitus for more than ten hours had 
the highest percentages $(63,2 \%)$ of good practice scores. On the other hand, dentists who attended diabetes courses less than one hour (22\%) had the highest percentage of poor practice scores. This is most probably attributed to the higher awareness they get when attending continuing education courses, and consequently reflected on their behavior. The present findings showed low level of practice among the study sample regarding diabetes. The knowledge aspect of the questionnaire clearly depicted that the participants had theoretical knowledge about certain aspects of diabetes but lagged behind when it came to the management of medical emergencies in the dental office.

\section{CONCLUSIONS}

However, most of dentists felt that they have an important role in the provision of preventive measures against the oral complication of diabetes mellitus and oral health education of the patients about the same issue.

\section{Limitation of the study:}

- Difficulty in approaching dentists due to their overloaded work and different schedules.

- Some participants refused to answer the questionnaire due to tight schedules or lack of interest.

- The absence of dentist in certain areas especially in rural areas.

\section{CONFLICT OF INTEREST}

The authors declare that they have no conflicts of interest

\section{REFERENCES:}

1. Saxena K, Sharma ML, Vijay B, Dhillom M. Knowledge, Attitude and Practice assessment of dental professionals towards diabetes. J Dent Specialities. 2016; 4:113-8.

2. World Health Organization. Prevalence of diabetes mellitus in the Middle Easter countries.Cited in 2004:http:www.who.int/diabetes/facts/world_figures/e n/index.html.

3. Bener A. Prevalence of diagnosed and undiagnosed diabetes mellitus and its risk factors in a populationbased study of Qatar. Diabetes Res Clin Pract. 2009;84: 99-106.

4. Eldarrat A. Diabetic patients: Their knowledge and perception of oral health. Libyan J Med. 2011;6:56916.

5. Janket SJ, Wightman A, Baird AE, Van Dyke TE, Jones JA. Does periodontal treatment improve glycemic control in diabetic patients? A meta-analysis of intervention studies. J Dent Res. 2005; 84:1154-9.

6. Darré L, Vergnes JN, Gourdy P, Sixou M. Efficacy of periodontal treatment on glycaemic control in diabetic patients: A metaanalysis of interventional studies. Diabetes Metab. 2008; 34:497-506.

7. Simpson TC, Needleman I, Wild SH, Moles DR, Mills EJ. Treatment of periodontal disease for glycaemic control in people with diabetes. Cochrane Database Syst Rev. 2010; 12:CD004714.

8. Teeuw WJ, Gerdes VE. Loos BG. Effect of periodontal treatment on glycemic control of diabetic patients: A systematic review and meta-analysis. Diabetes Care. 2010; 33:421-7.

9. Eke PI, Beckles GL. Dental visits among dentate adults with diabetes - United States, 1999 and 2004. MMWR Morb Mortal Wkly Rep. 2005;54:1181-3.

10. Hema TS. Dentists' attitudes and practices related to diabetes in dental setting in Hubli-D Harwad City. IJDHS. 2014; 1:879-89.

11. Promsudthi A, Pimapansri S, Deerochanawong C, Kanchanavasita W. The effect of periodontal therapy on uncontrolled type 2 diabetes mellitus in older subjects. Oral Dis. 2005; 11:293-8.

12. Faul F, Erdfelder E, Lang A-G, Buchner A. GPower 3: A flexible statistical power analysis program for the social, behavioral, and biomedical sciences. Behav Res Methods. 2007; 39:175-91.

13. Boyed LD. Dental hygienists association survey of diabetes knowledge and practices of dental hygienists. J Dent Hygiene. 2008; 82:5-8.

14. Daniel W. Biostatistics. A foundation for analysis in the health science. $6^{\text {th }}$ ed. NY: John Wiley and sons Inc; 1995.

15. Esmeili T. Dentists' attitudes and practices related to diabetes in the dental setting. J Public Health Dent. 2010; 70:108-14. 